\title{
Street Mapping of Ife Metropolis, Osun State, Nigeria
}

\author{
Idowu Sunday Kolawole, Taofik Abayomi Alaga, Samson Akintunde Ogunyemi, \\ Oladimeji Samuel Popoola, Mustapha Olayemi Oloko-Oba
}

Advanced Space Technology Application Laboratory (ASTAL), Cooperative Information Network (COPINE), National Space Research and Development Agency (NASRDA), Obafemi Awolowo University Campus, Ile Ife, Nigeria

Email: kolawolest@gmail.com

Received 21 September 2015; accepted 14 June 2016; published 17 June 2016

Copyright (C) 2016 by authors and Scientific Research Publishing Inc.

This work is licensed under the Creative Commons Attribution International License (CC BY).

http://creativecommons.org/licenses/by/4.0/

c) (i) Open Access

\begin{abstract}
The importance of Remote Sensing and Geographic Information System in map making cannot be overemphasized because of its ability to integrate spatial data with non-spatial data and also communicate the resulting information in a way that everyone would understand. Several works have taken advantage of the abilities of these technologies to produce street maps using High Resolution Images. The increase in development in Ile Ife, Osun State, Nigeria, has brought about navigation challenge and associated difficulties. This work intends to produce a street map that will ease navigation within the study area and help in road network analysis, site suitability analysis etc. Aerial Photographs, captured in the year 2009 and GeoEye1 Satellite Image of 2011 were used to extract the road network of Ife Metropolis. The image was imported into ArcGIS environment, where the database was created having feature datasets such as roads and special features. To have all the elements in vector format, the image was digitized. The street names collected from the field work was inputted into the database and then subjected to cartographical processes. 512 Roads were captured within four classes of Road Network namely Express road (5), Secondary Road (25), Primary Roads (22) and Street Road (460). This field work revealed that a larger percentage of the roads were not paved, while most of the paved ones have deteriorated and the newly constructed ones were not documented. It also showed that some of the roads were not named according to the standard and some were not named at all. From this study, we recommend that the naming system should be standardized across the study area. It is also recommended that provision should be made for street map revision on a yearly basis so as to account for changes.
\end{abstract}

\section{Keywords}

Remote Sensing, Geographic Information System, Aerial Photograph, Digitization 


\section{Introduction}

A map is a model of part of the earth surface showing the shape, and position of different countries, political boarders, natural features such as rivers and mountains, and artificial features such as roads and buildings. A map can also give you particular type of information about a certain area on the surface of the earth.

It can be made so simple and specific that it shows direction of travel from one place to another. Reconnaissance technologies such as aerial photograph and satellite based sensing have come to man's aid in quest to understand and preserve his environment. This advancement has given the map makers new tools for creating and updating maps as well as allowing mapping in details which is of great use most especially in planning of urban areas. Maps are specially designed to serve several purposes and answer specific questions such as street maps, utility maps etc.

A street map is a type of map that contains the position and names of streets. A street map is useful in areas such as: planning enumeration areas by demographers; navigation for tourists; salesmen; firemen; police; security agent; tax collectors, postal service etc. [1]. It can also be defined as a graphic portrayal of a town or city, showing the positions and names of all the streets; major/minor highways and roads, railroads, tracks and other points of interest and the general road network. It is a form of map that details roads and transport links [2].

A street map has the ability to provide answers to question like: where a road is; where it leads to; the distance and type, the best route between two points or the shortest point [3]. Also some of the usage of street map as: for locating houses and streets; car navigation; planning of transportation, trips and driving directions; and for planning of movement and provision of facilities, goods and services [2].

Street map stands as a basic datum that can also help researchers conduct good research such as emergency response studies, proximity and accessibility studies. This can be designed and consistently updated to accommodate further developments using a robust technology such as GIS and remote sensing.

The level of urbanization in the developing world indicates that more people now live in cities than before. Ife Central is the heart of Ile-Ife, considering the fact that the Obafemi Awolowo University, the Teaching Hospital and virtually all the banks in Ile-Ife are located in Ife Central, which attracts millions of people every day especially visitors either for admission, jobs, health services or business transactions, who finds it difficult to locate most of the streets thereby ending their movements and activities unaccomplished.

New streets are created everyday as new structures are constructed for rent, hotels, restaurants as well as other purpose. Road network helps in creating Street Network Information Management System (SNIMS) for better administration of the local government area.

As at the time of this study, creating a new road network and the management of existing road network seems difficult and cost demanding due to non-availability of cohesive information on road network architecture.

In addition, most of the available revenue generating infrastructures located within the metropolis such as tourist sites, health facilities, markets, sawmills etc. have been affected by poor road network.

The need for the use of remotely sensed data for mapping, naming and numbering of the streets in Ife Metropolis using Geographic Information System (GIS) techniques cannot be over emphasized.

\section{Literature Review}

The advent of industrialized/information age which was as a result of the advancement in Information and Communication Technology has brought us to a point where maps can better be used to represent information about a phenomenon on the earth surface with less stress and skills [4]. This was not so in some decades ago because of the complexities and skillfulness involved in map making which makes it to be restricted to a privileged few such as surveyors, cartographers and geographers. Some of these maps which can either be static or dynamic, presenting information which represents the spatial distribution of geographic features in nature that can be used by navigators, researchers, town planners, architects, marketers etc. It is also expected that some of these maps (static) will not be giving the user perfect information representing what is obtainable on the surface of the earth after it has been produced because of the time factor involved [5].

One of the major challenges that industrialization and urbanization has brought is the complexities of urban transportation system and inability to monitor the fast increase in new streets and structures. This will definitely lead to the emergence of slums and uneven distribution of social amenities. In addition to this, it becomes very difficult to move goods and people from one end to the other easily because of the complexities in the arrangement or multiple streets leading to the point [6]. 
Due to these complexities, it will be difficult to answer questions such as "How do I safely ride to this school on my bike?" or "Where can I get my shoes repaired?" and even more pressing questions, like "How do I reach the nearest hospital in case of an emergency?" Being able to define where community or commercial buildings are and show others the relationships between locations and how to get to there has always been useful, even essential, to humans everywhere. Road network plays an important role in solving these complexities in the urban life as it helps accessibility and promotes urban planning and development [7]. It was observed that in Africa and Nigeria in particular, movement of goods and services, social and economic development of the country are dependent on good road network as road is the major means for transportation [2].

To solve these challenges, street maps are produced to provide information about the roads as faithful as possible in such a way that it can accommodate changes that are rapidly occurring. From reviews, no map of Ile Ife has been published that is as recent as what this work will present. In recent time, several activities and changes have been going on in Ile Ife that has necessitated the creation of new streets and roads hence a need for an updated map of Ile Ife. Culturally, Ile Ife is taken to be the source of Yoruba race with a lot of tourist centres scattered all over the city that will require a map for a visitors and tourist to navigate their way.

Street map is made possible with the use of Remote Sensing and GIS technology [8] [9]. This is because of the ability of remote sensing technology to capture high resolution satellite images of the surface of the earth showing various features and infrastructures. Some studies have shown that major roads and railways are easily identified on high resolution satellite images with the accuracy between 90 percent and 100 percent [10] [11]. Due to tree canopies or weak contrast of the satellite image, Minor roads and tracks are not easily visible with the accuracy ranging from 23 percent to 64 percent depending on categorization. It was also noted that the accuracy of urban street mapping using satellite imageries depends on the image geometric accuracy and extractable map scale based on adopted standards and its information content [12]. Thus for updating and producing road infrastructure map, $1-30 \mathrm{~m}$ resolution imagery could be used in area of minimum tree density but to obtain an accurate, precise and quality street map, a high resolution $(0.25-0.5 \mathrm{~m})$ image must be used. This led us to the use of Geo- eye image for this work.

The information captured by the satellite image is further processed and analyzed using Geographic Information System. GIS is a robust technology that can manipulate, analyze and integrate non spatial (Information about the data captured) with the spatial to solve the desired problem. With the use of these technologies, the problem of providing static maps with information about changes is been solved. It will solve the challenge of map revision which is aimed at keeping the map up-to-date and at the same time maintain accuracy [13]. GIS can also be used to determine best path to two points, the location of a new service center (Health facilities, Fire stations, Power Stations etc.) and assignment of areas of influence of a centre can be determined [14].

\section{Material and Method}

\subsection{Study Area}

Ife is an ancient town in Yoruba history and is regarded as the cradle of civilization. Administratively, Ile-Ife has three local governments namely Ife Central, Ife North and Ife East. The secretariat of Ife Central Local Government, Ife North Local Government and Ife East Local Government is situated at Ajebamidele, Ipetumo$\mathrm{du}$ and Oke Ogbo respectively. The population of the three LGAs according to the 2006 National Census is put at $167,254,153,694$ and 188,027 respectively.

Geographically, Ile- Ife lies on longitude $4^{\circ} 69^{\prime} \mathrm{E}$ and latitude $70^{\circ} 50^{\prime} \mathrm{N}$ (Figure 1). The climate is humid tropical with distinct wet and dry seasons. Like every other Southwest area, the rainy season starts April to October while the dry season lasts October to March.

\subsection{Data}

Primary and secondary data were used for this work, these includes:

- Attribute data of marked features and street annotation of the study area

- Aerial Photograph, $0.25 \mathrm{~m}$ Resolution, 2009

- GeoEye-1 0.5 m Spatial Resolution colour image of December, 2014

- Landsat 8,30 m, Spatial Resolution, 2014.

\subsection{Methodology}

The mapping of the street network was basically done by digitizing the roads/streets within the study area from 


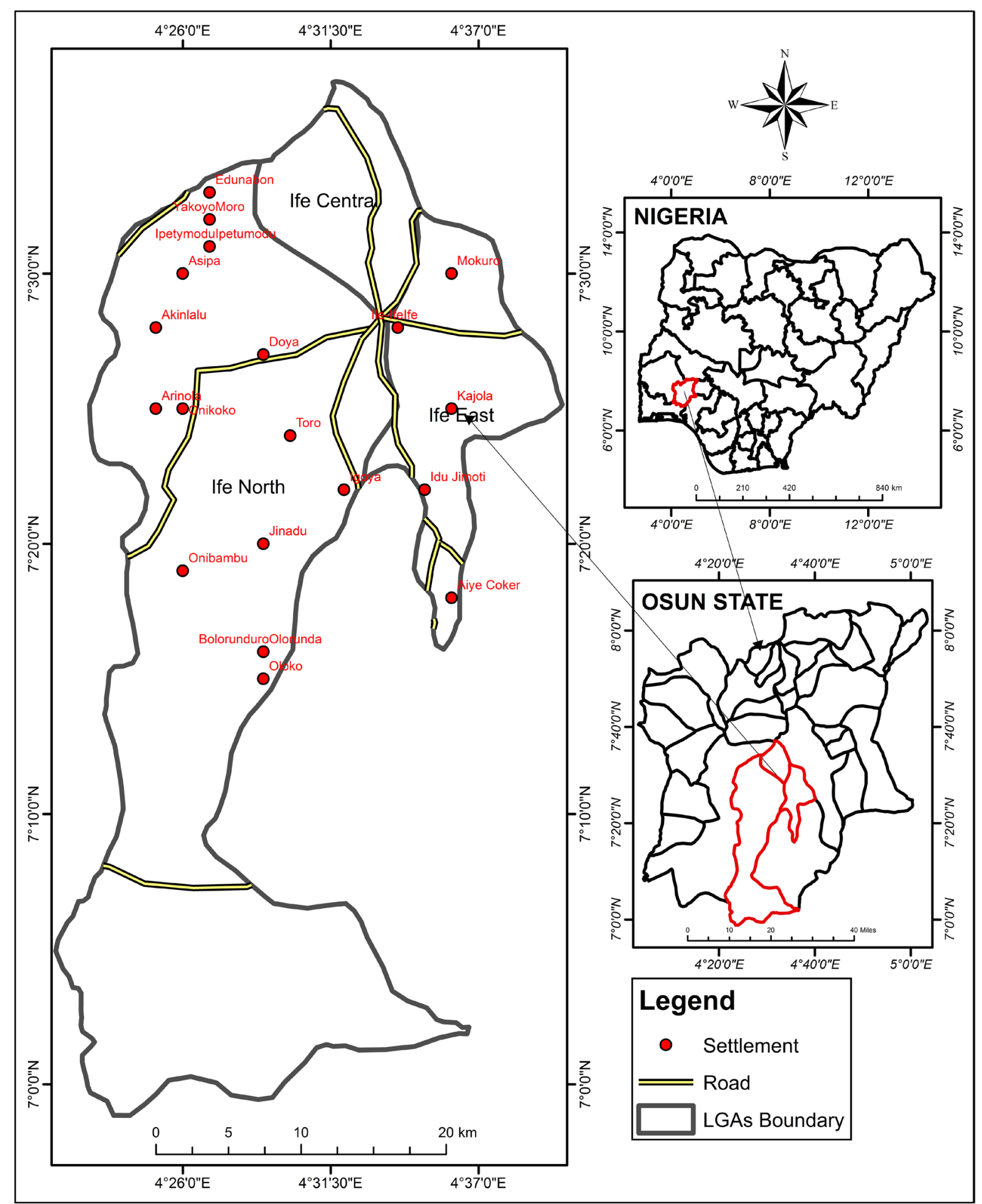

Figure 1. Map of the study area.

the geo eye-1 image, 2014 and applying cartographic processes as shown on the flow chart in Figure 2. The Geo eye satellite image was imported into the GIS environment after setting the data frame to WGS 1984 UTM Zone $31 N$. Database was created for the street with fields showing the road names, road types (Express, Primary, Secondary and Street). The roads were then digitized and categorized appropriately. The names of the street 


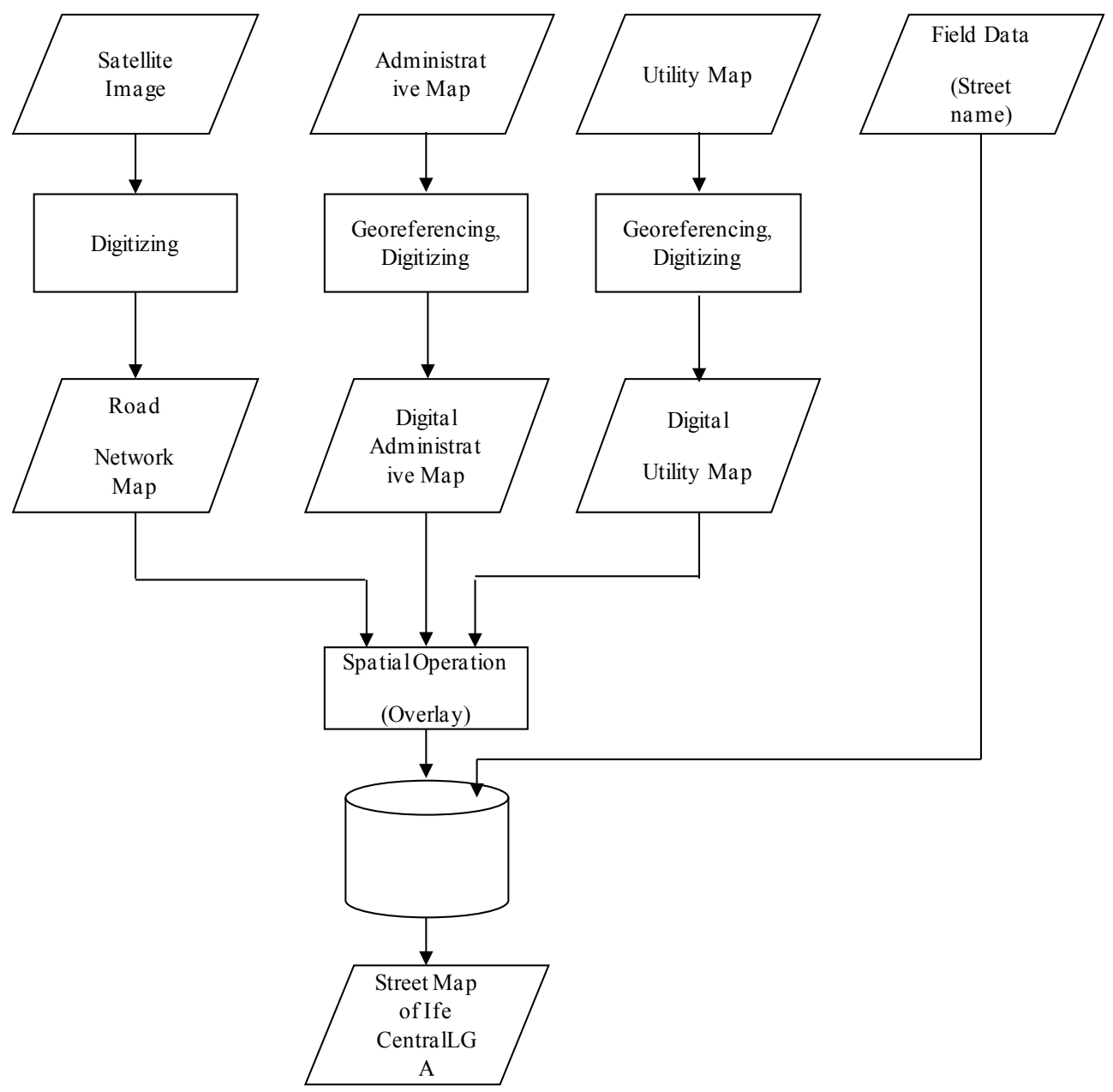

Figure 2. Flow chart of the methodology.

were collected through the field work conducted across the streets in Ife Central, also special features were also identified on the field map. These data and information were inputted into the database already created during the process of capturing the roads appropriately and then subjected to cartographical procedures for clearer visualization and representation.

So as to properly represent the various land use within the study area, the Landsat Imagery was classified into 5 classes namely: Built up, Shrubs, Shrubland, Forest and Waterbody. The street map was overlayed on the created street/road map. Also the elevation data for the study area was captured from Google site using kml application which was further used to generate the DEM of the area. The DEM was overlayed with other results generated to produce the street map of Ife metropolis.

\section{Results and Discussion}

At the end of this work, we present a street map of Ife Metropolis showing 512 roads that were captured and labelled within the study area. The roads were categorized as shown in Table 1 and it is also represented in Histogram in Figure 3. The foot paths were also captured but were not named since they were not given particular names. Figures 4-7 displayed some captures within Ile Ife showing the roads and the annotations clearly. There are some street within Ile Ife that were not properly named or have a general name that is not good for descriptive purposes.

Figure 4 is showing some part of Obafemi Awolowo University Campus around the central campus area.

Figure 5 is showing some part of Igboya Street, Aladanla Street, Odi-Olokun Street, Moore Road and some special features like Ife City Stadium, Seventh Day Adventist School and Ilesha Motor Park. 


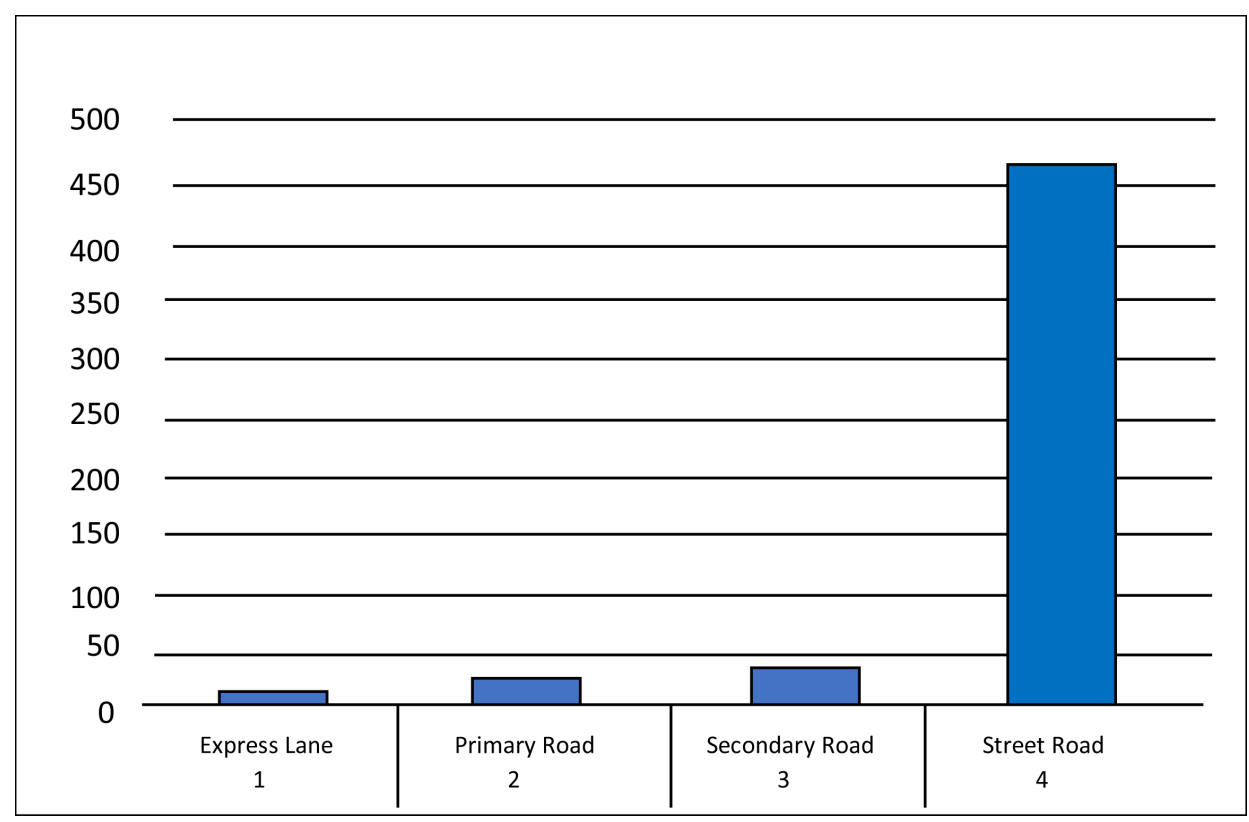

Figure 3. Histogram representing the type od roads and the numbers captured within the study area.

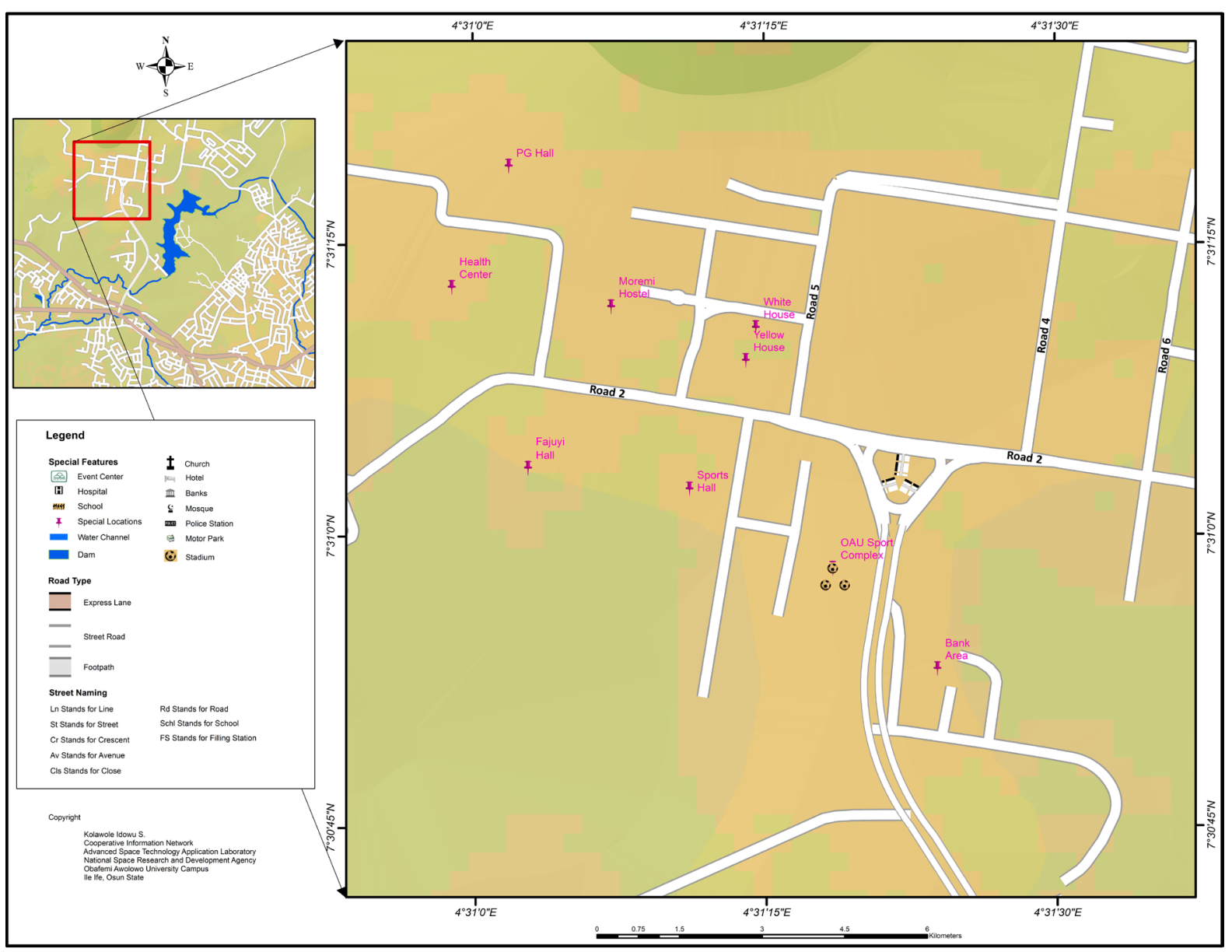

Figure 4. A View of part of Obafemi Awolowo University Campus. 
Table 1. Table showing the types of road captured.

\begin{tabular}{ccc}
\hline S/N & Type of Road & Number in Each Category \\
\hline 1 & Express Lane & 5 \\
2 & Primary Road & 22 \\
3 & Secondary Road & 25 \\
4 & Street Road & 460 \\
\hline
\end{tabular}

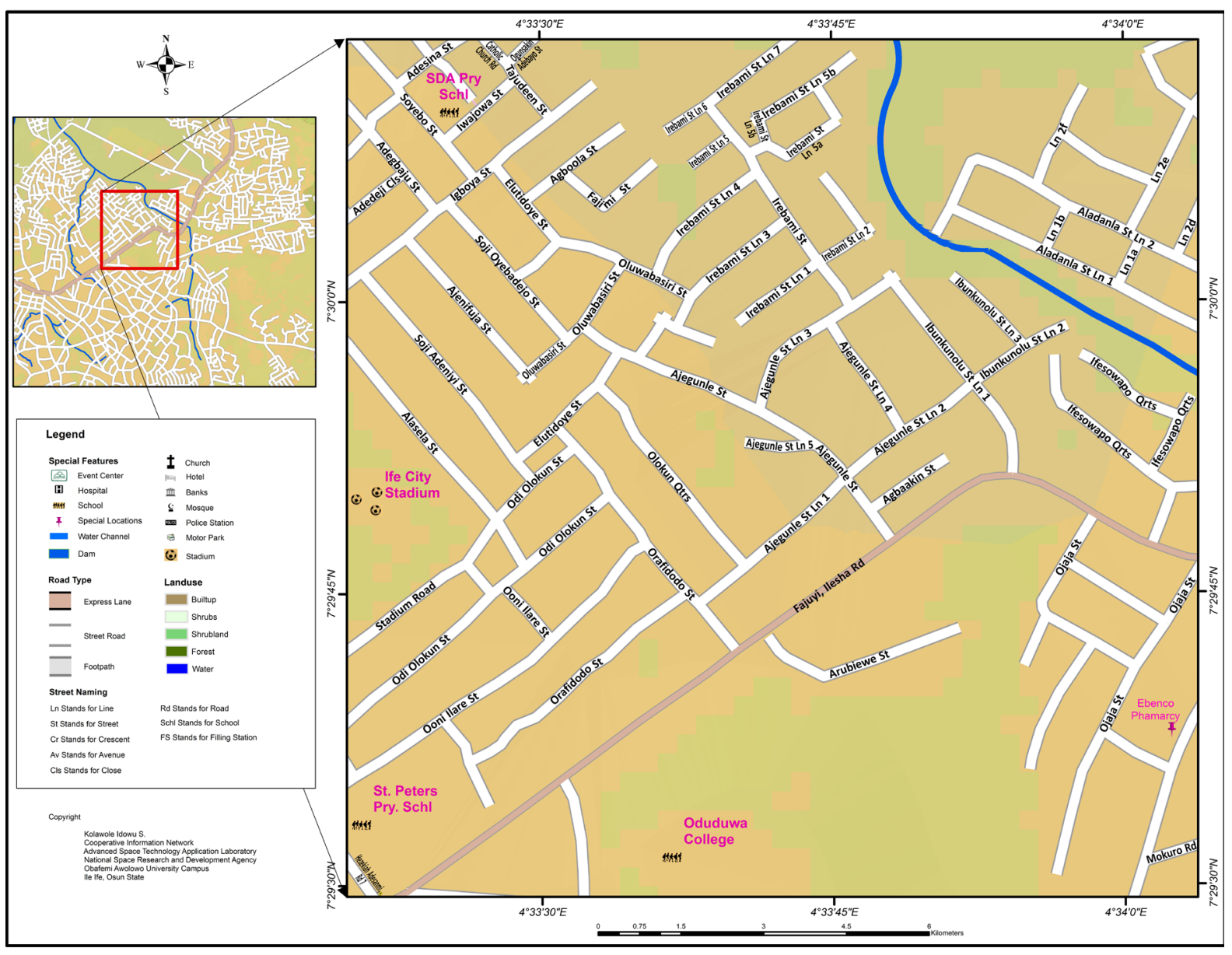

Figure 5. A View of Igboya Community and Environs.

Figure 6 is showing some part of Parakin, Hezekiah Adesanmi also known as Road 7, Mbabi Mbayo Street, Igboya Street and other features such as Oluorogbo Grammar School, Aquarium Event Center, Mercy Land Church.

Figure 7 shows Akarabata, Town Planning Road, Obalufon Street, Catholic Mission Road, Some part of Eleyele Layout, some part of Aderemi Street and locations of some special features like the major banks in Ile Ife such as Fidelity Bank, Diamond Bank, Access Bank, Zenith Bank. It also shows some other special; features like Winners Chapel Lagere and St. David School.

\section{Conclusion}

Geographic Information System and Remote Sensing has given us the opportunity to present an up-to-date map of any place on the surface of the earth. It can also provide opportunity for revision of any map as fast as possible. With the help of this, map navigation is made easily in Ile Ife Metropolis which will in turn aid a lot of de- 


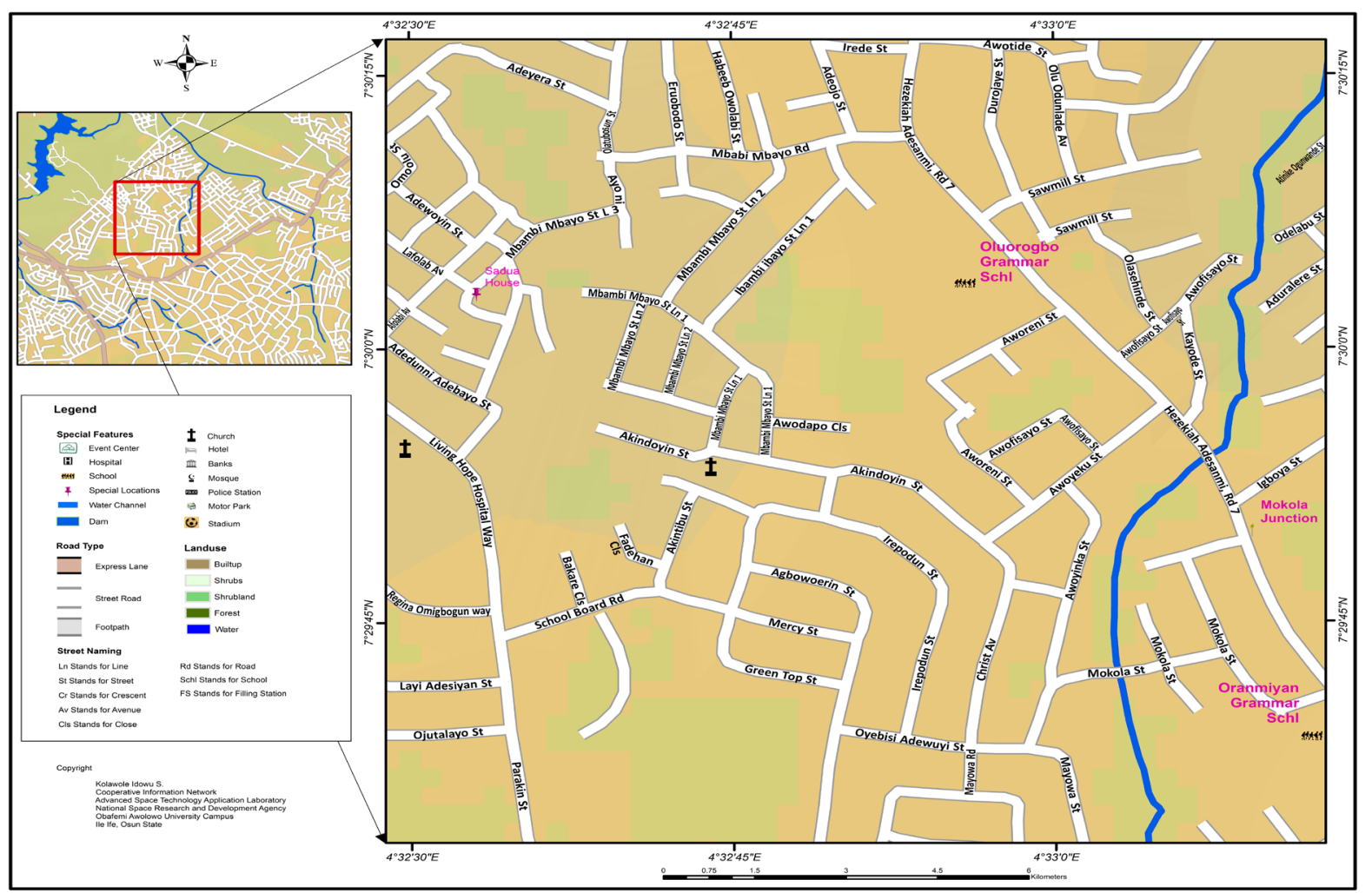

Figure 6. A View of Parakin Community and Environs.

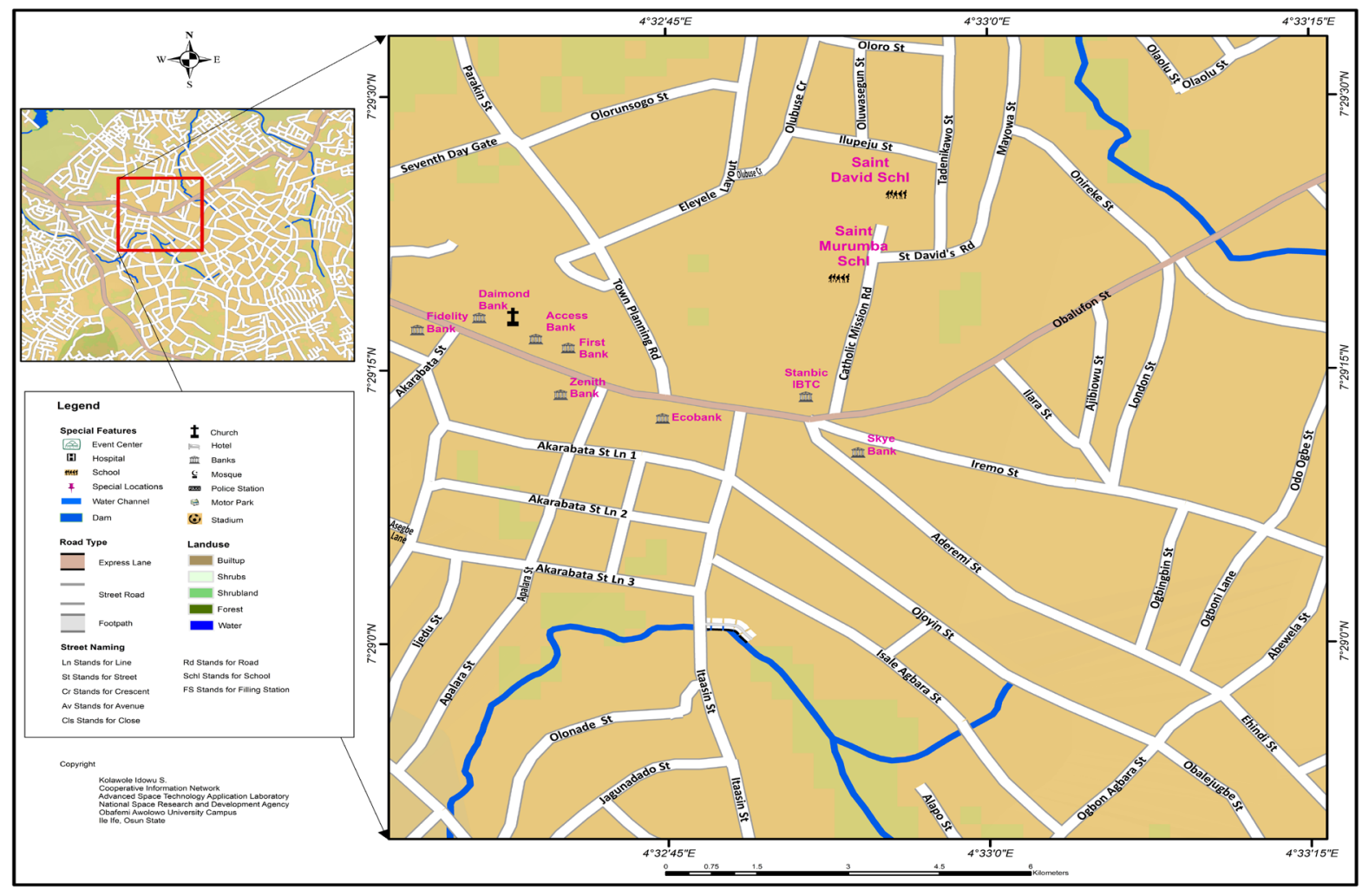

Figure 7. A View of Akarabata Community and Environs. 
velopment in several areas such as Infrastructural Development and evenly distribution, tourism, marketing etc.

\section{Recommendation}

This work revealed that several roads were not properly named. Therefore, we recommend that the local government should adopt a standard format for all the street and implement it. Also we recommend that small sign board or notice board should be used to identify the beginning and the end of each street so as to aid navigation. It's also important to create street map for the whole Local Government in Ife (Ife Central, Ife North, Ife East, and Ife South) and Osun State at large.

\section{References}

[1] Ezra, P.H. and Kantiok, L. (2007) The Relevance of Maps in the Control of Urban Slums. Proceedings of the 29th Annual Conference of NCA, Kaduna, August 2007, 21-25.

[2] Udoh, I.B. and Igbokwe, J.I. (2014) Production of Revised Street Map of Uyo Urban Area, Nigeria Using Remote Sensing and GIS Approach. International Journal of Engineering Research and Technology, 3, 1792-1799.

[3] Musa, D. and Yusuf, R.K. (2007) Geographic Information System (GIS): A Tool for Land Resources Management in Nigeria. Proceedings of the 29th Annual Conference of NCA, Kaduna, August 2007, 10-15.

[4] Haklay, M. and Weber, P. (2008) Open Street Map: User-Generated Street Maps. University College, London.

[5] Keates, J.S. (1973) Cartographic Design and Production. Longman Inc, New York.

[6] Tini, N.H. and Peter, Y. (2010) Application of Satellite Remote Sensing, GPS and GIS for Mapping Road Network in Mubi Metropolis, Adamawa State, Nigeria. Journal of Environmental Sciences and Resource Management, 2, 56-64.

[7] Samadzadegan, F., Azizi, A. and Hahn, M. (2004) Automatic Change Detection of Urban Geospatial Databases Based on High Resolution Satellite Images Using Ai Concepts. Commission VI, WG VI/4.

[8] Paulsson, B. (1992) SPOT Data for Urban Land-Cover Mapping and Road Map Revision. International Achieves of Photogrammetry and Remote Sensing, 29. 352-357.

[9] Vernar, R.K., Kumari, S. and Tiwary, R.K. (2008) Application of Remote Sensing and GIS Technique for Efficient Urban Planning in India. Paper Presented at Geomatrix 2008.

[10] Salge, F. and Roos-Josserand, M.J. (1988) Apport des images satellites a la base de donn6es cartographiquesd e l'IGN: Resultats de l'experience Franco-Canadiennes ur le contenu des images. Presented at the International Symposium on T'opographic Applications of SPOT Data, Sherbrook DC, Anada, 13-14 October.

[11] Manning, J. and Evans, M. (1988) Revision of Medium Scale Topographic Maps Using Space Imagery. International Achieves of Photogrammetry and Remote Sensing, 27, 233-245.

[12] Jensen, V. Introductory Digital Image Processing. 3rd Edition, Pearson Educational International, NJ.

[13] Abbas, I.I., Adama, Y.A. and Koje, J.A.U. (2010) Street Mapping Using Remotely Sensed Data and GIS Technique. Research Journal of Applied Sciences, Engineering and Technology, 2, 191-197.

[14] Lupien, A.E., Moreland, W.H. and Dangermond, J. (1987) Network Analysis in Geographic Information Systems. Photogrammetric Engineering and Remote Sensing, 53, 1417-1421. 


\section{Submit or recommend next manuscript to SCIRP and we will provide best service for you:}

Accepting pre-submission inquiries through Email, Facebook, Linkedin, Twitter, etc A wide selection of journals (inclusive of 9 subjects, more than 200 journals)

Providing a 24-hour high-quality service

User-friendly online submission system

Fair and swift peer-review system

Efficient typesetting and proofreading procedure

Display of the result of downloads and visits, as well as the number of cited articles

Maximum dissemination of your research work

Submit your manuscript at: http://papersubmission.scirp.org/ 